\title{
Improving the Performance of Automotive Engines and Tribological Behavior of the Piston Ring Assembly Using Nanomaterials as Smart Nano-Lubricant Additives
} Mohamed Kamal Ahmed Ali ${ }^{1,2}$

\begin{abstract}
${ }^{1}$ Automotive and Tractors Engineering Department, Faculty of Engineering, Minia University, El-Minia 61111, Egypt. ${ }^{2}$ Hubei Key Laboratory of Advanced Technology for Automotive Components, Wuhan University of Technology, Wuhan 430070, China. E-mail: eng.m.kamal@ mu.edu.eg (M.K.A. Ali).
\end{abstract}

\section{Abstract:}

One of the most important objectives of the studies worldwide is to improve the performance of automotive engines to reduce fuel consumption and environmental pollution. Accordingly, the principal motivation of this research study is improving the tribological behavior of the piston ring/cylinder liner interfaces as a promising and straightforward approach in automotive fuel economy and increasing engine durability using $\mathrm{Al}_{2} \mathrm{O}_{3}$ and $\mathrm{TiO}_{2}$ nanomaterials as smart nanolubricant additives that adapted to different operating conditions by replenishing mechanisms antifriction and anti-wear in automotive engines.

Keywords: Nano-Tribology, Nano-Lubricants, $\mathrm{Al}_{2} \mathrm{O}_{3}$ and $\mathrm{TiO}_{2}$ Nanomaterials, Tribological Behavior of Piston Ring Assembly, Gasoline Engine Performance, Fuel Economy.

\section{Introduction}

The friction between two sliding surfaces is probably one of the oldest problems in mechanics. The friction in automotive engines is a principal cause of energy dissipation. Current challenges for improving the tribological behavior in automotive engines require lubricants that adapted to different operating conditions by replenishing mechanisms for reducing the friction and wear. Total power generated by the engine is decreased in the range $17 \%$ and $19 \%$ because of the total frictional losses. To reduce the total frictional losses in automotive engines, it is imperative to improve the tribological performance of the piston ring assembly because it makes a contribution of about $40 \%$ to $50 \%$ in the total frictional losses. Therefore, a situation that presents a key challenge for researchers and designers with regard to finding ways of enhancing the tribological characteristics of piston ring assembly while achieving a reduction in fuel consumption. To solve this problem, most designers and researchers have focused on Nanotribology in internal combustion engines as the main strategy for minimizing frictional power losses, excessive heat 
generation and the wear of contact surfaces, in a manner that will ultimately lead to an improved performance of automotive engines.

The principal motivation of this thesis focuses on tribological behavior as a solution for reducing fuel energy consumption in automotive engines. The piston assembly plays a vital role in the efficient operation of the internal combustion engine. Existing and future automotive engines would require more efficient engine oils, however the mechanical interfaces are usually lubricated by a blend of lube films and solid tribofilms. In recent years, nanoparticles have started to play more important roles as lubricant additives for their potential in emission reduction and improving fuel economy. The nano-lubricants we propose to develop combine benefits of both solid and liquid lubrication, and have the potential to offer significant environmental and tribological benefits, offering higher efficiencies, and extending the life of components. As a result of limited reserves of crude oil, employing nano-lubricant additives is considered as an accepted and attractive oil lubricant modification technique which is widely adopted since it does not need any major hardware modifications.

Furthermore, new efficiency and emission standards imposed on vehicles have been the main driving force behind the development of cleaner and more fuel-efficient lubricants over the years. Commercially, $90 \%$ of lubricants are composed of hydrocarbon molecules and the rest are additives governing their behavior. For decades, organic phosphorous and sulfide compounds have played important roles in friction modification and wear resistance. For engine efficiency improvement, it is desirable exploring new ways to replace the use of environmental harmful additives which cause adverse emissions (zinc dialkyldithiophosphate (ZDDP)) and other additives that contain sulfated ash, phosphorous and sulphur, without compromising on tribological performance for automotive engines with environmentally friendly additives such as ionic liquids and nanoparticles

The goal of this study is to develop an effective methodology via formulation of $\mathrm{Al}_{2} \mathrm{O}_{3}$ and $\mathrm{TiO}_{2}, \mathrm{Al}_{2} \mathrm{O}_{3} / \mathrm{TiO}_{2}$ hybrid nano-lubricants, which can be used to obtain the improving of the tribological characteristics of a piston ring assembly under different lubrication regimes for fuel economy, long life span for engine parts, and a cleaner environment. The specific aims of this research are as follows:

1. Studying the effect of piston ring dynamics on basic tribological parameters for help in an understanding of the tribological parameters which, contribute towards the improvement of engine performance. 
2. Design and develop a novel lubricant additive that can provide the friction reduction with durability in automotive engines.

3. Design tribometer test bench to mimic the sliding reciprocating motion of the piston ring/cylinder liner interface in an engine according to ASTM G181 for measuring the friction. Furthermore, to link tribological tests in the laboratory with actual engine performance.

4. Conduct a comprehensive tribological performance evaluation in terms of friction, wear and scuffing for the piston ring/cylinder liner interfaces using smart nano-lubricants.

5. This study aims for revealing the mechanisms of nano-lubricants, which could reinforce an increased life span for engine components (improved engine durability).

6. To explore self-replenishment mechanisms of self-assembled tribofilms on the sliding contact interfaces lubricated by $\mathrm{Al}_{2} \mathrm{O}_{3} / \mathrm{TiO}_{2}$ hybrid nano-lubricants.

7. Improving the efficiency of gasoline engines, reducing maintenance requirements and longer service intervals for lube oils and improving the fuel economy in automotive.

The use of nanomaterials as nano-lubricants additives is a recent idea. Major advantages of the nanomaterials compared to conventional lubricant additives as follows:

a. Nanometre size of particles allows them to enter the contact area easily.

b. They are often efficient at ambient temperature. Thus, no induction period is necessary to obtain interesting tribological properties.

c. Tribochemical reactions are limited, compared to traditional additives.

d. Activation of particle surface.

e. Increase of surface area and extreme small sizes.

f. Nanomaterials sized smaller than $100 \mathrm{~nm}$ have thermal conductivities higher than those of the fluids.

g. The lower elastic modulus as the main reasons for the excellent lubricating properties.

The selection of nanomaterials is a very important step. The reasons for choosing $\mathrm{Al}_{2} \mathrm{O}_{3}$ and $\mathrm{TiO}_{2}$ nanomaterials for study as follows:

a. $\mathrm{Al}_{2} \mathrm{O}_{3}$ and $\mathrm{TiO}_{2}$ nanoparticles are mostly appropriate for many environmental applications.

b. $\mathrm{Al}_{2} \mathrm{O}_{3}$ and $\mathrm{TiO}_{2}$ provide excellent tribological properties and widely applied as nano-lubricant additives or solid lubricant.

c. $\mathrm{Al}_{2} \mathrm{O}_{3}$ and $\mathrm{TiO}_{2}$ provide good mechanical and thermal behavior.

d. $\mathrm{Al}_{2} \mathrm{O}_{3}$ and $\mathrm{TiO}_{2}$ nanomaterials are categorized as ceramic materials. 
e. The hybrid nanoparticles exhibited properties that do not exist in the individual material as well as the synergistic effect of the nanoparticles.

f. $\mathrm{Al}_{2} \mathrm{O}_{3}$ and $\mathrm{TiO}_{2}$ nano-lubricants are an economic and inexpensive, for example 100 gram from nanomaterials costs $100 \mathrm{RMB}$, while the engine needs approximately 4 grams (4 RMB) per oil replacing.

\section{Some Results}
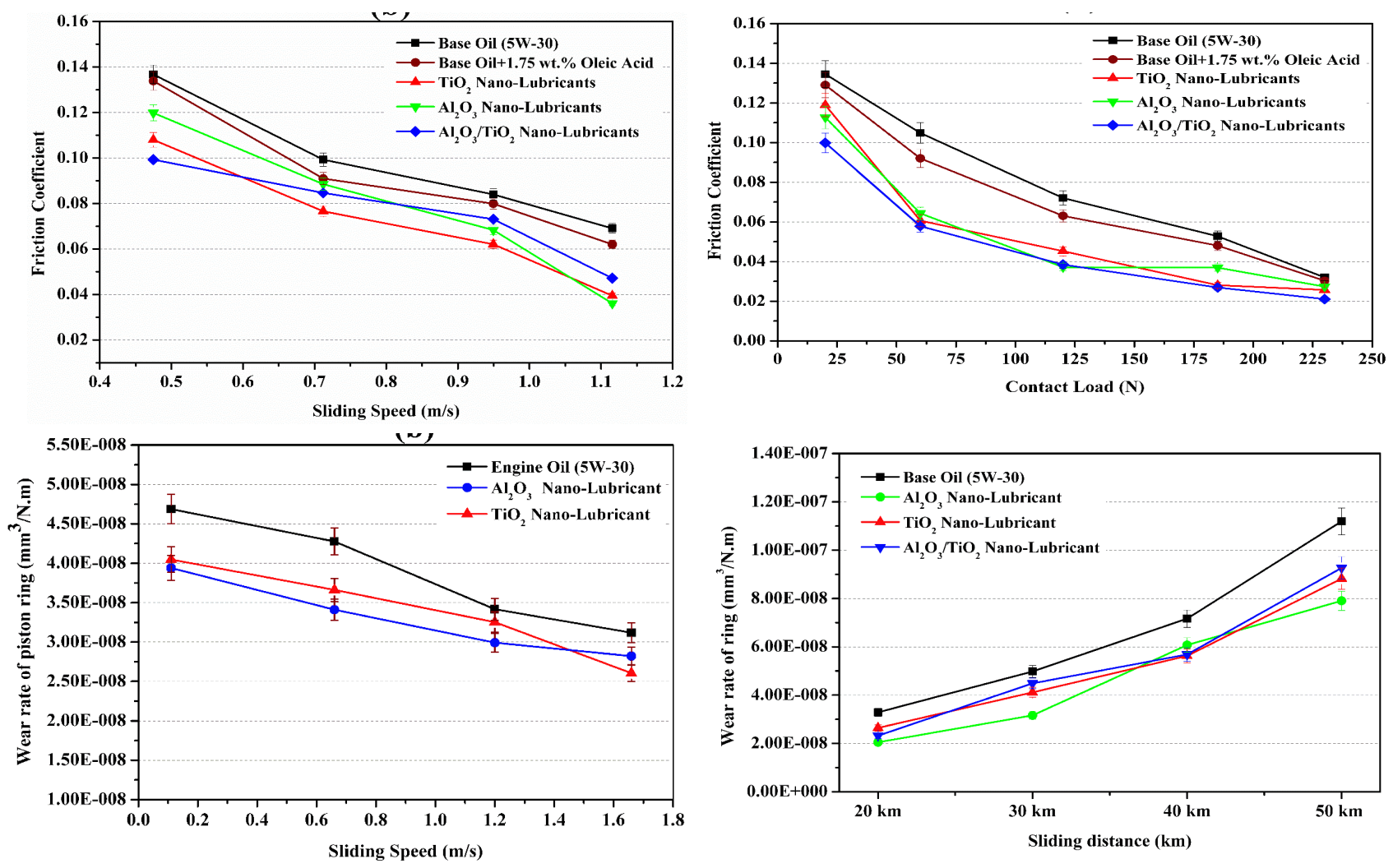

Fig. 1. Tribological behavior of the piston ring assembly using nanomaterials as smart nanolubricant additives [3, 4, 7].

The results in Fig. 1 showed a decrease in friction coefficient and wear with increasing sliding speed and load. But, the wear rate increased with increasing sliding distance because of the change from tribo oxidation to adhesion. The main reasons for the decrease in friction coefficient for nanolubricants is the ability of the nanoparticles to change pure sliding friction to rolling friction and formation tribo-film on the frictional surfaces. From the results, $\mathrm{Al}_{2} \mathrm{O}_{3}$ nano-lubricant was more 
effective in improving the anti-wear via tribo-film formation as a solid lubricant, but $\mathrm{TiO}_{2}$ nanolubricant was more effective in reducing the friction coefficient by produce the rolling effect [5].

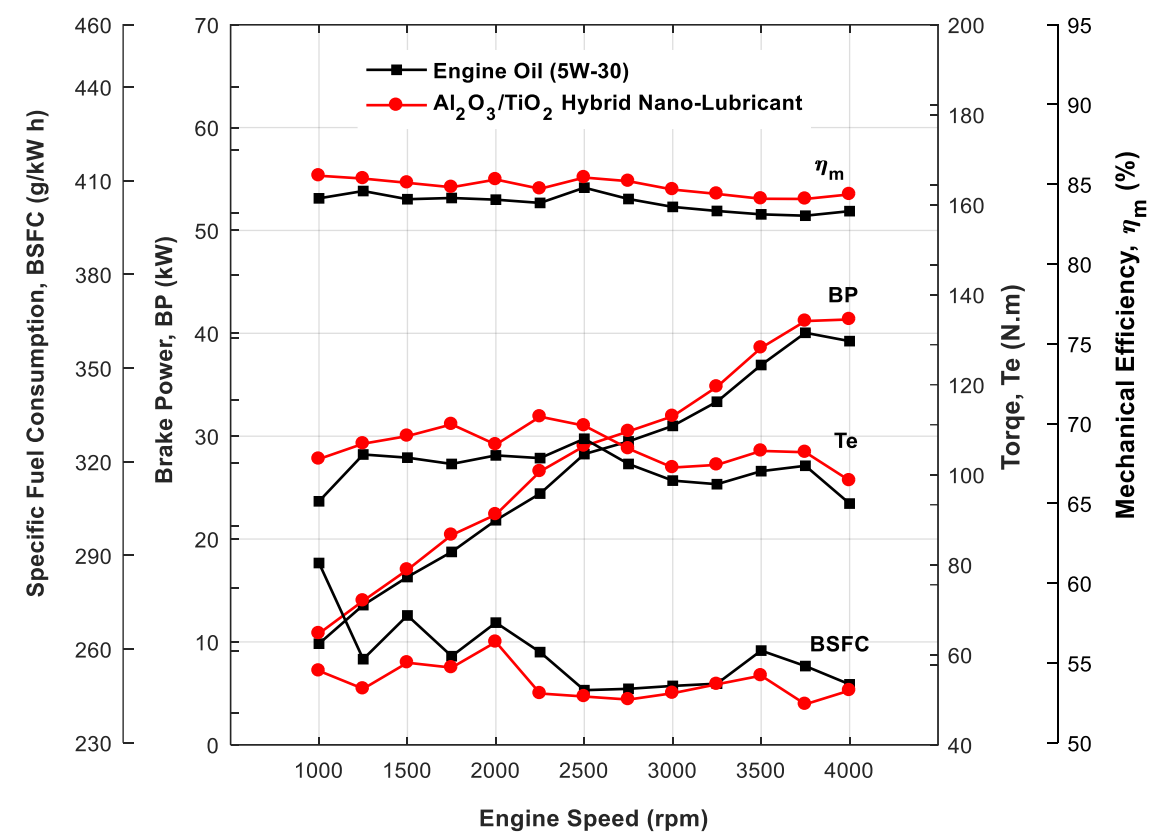

Fig. 2. Improving the performance of gasoline engines using $\mathrm{Al}_{2} \mathrm{O}_{3} / \mathrm{TiO}_{2}$ smart nano-lubricants $[1]$.

The results (Fig. 2) exhibited that the brake power and engine torque increased with the use of $\mathrm{Al}_{2} \mathrm{O}_{3} / \mathrm{TiO}_{2}$ hybrid nanolubricants in all specific operative conditions, as compared to the lube oil without nanoparticles (5W-30). The reason is that the total frictional power losses decreased by 5 $7 \%$ using hybrid nanolubricants. As a result, the mechanical efficiency of the engine improved in the range $1.7-2.5 \%$. Moreover, the fuel consumption reduced by approximately $16-20 \%$.

\section{Main Conclusions}

1. The friction coefficient decreased by $50 \%$ for the boundary lubrication regime, as compared with engine oil (5W-30). Hence, the frictional power losses of piston ring assembly were also reduced by $50 \%$ for the hybrid nano-lubricants. Furthermore, Nano-lubricants provide low kinematic viscosity and an increase in the viscosity index by $2 \%$. However, thermal conductivity was enhanced by $12-16 \%$. 
2. The results exhibited that the brake power and engine torque increased with the use of $\mathrm{Al}_{2} \mathrm{O}_{3} / \mathrm{TiO}_{2}$ hybrid nanolubricants in all operative conditions, as compared to the lube oil without nanoparticles (5W-30).

\section{Acknowledgments}

I would like to express my sincerest thanks to my supervisor Professor Hou Xianjun, for his invaluable support, advice and encouragement throughout this study. It has been a great pleasure and honour to work under the supervision of such a distinguished scholar. I would like to thank Professor Yan Fuwu for cooperating with me to work in Nano-Tribology field during the initial period of this study. I would also like to thank Professor Liqiang Mai for assistance in nanomaterials at State Key Laboratory of Advanced Technology for Materials Synthesis and Processing.

I would like to thank the Hubei Key Laboratory of Advanced Technology for Automotive Components, Wuhan University of Technology and the Chinese Scholarship Council for financial support (Grant Number 2014GF032). Moreover, special thanks for the Egyptian government for supporting my family and me during my $\mathrm{PhD}$ study. Throughout this study, members of technical staff have helped me and I would especially like to thank Mr. Lui Huagang. Particular mention must also be given to Eng. Peng Fuming for his time during tribometer design and engine setup. During the entire study, I have collaborated with many Chinese colleagues for whom I have great regard during my PhD study. My sincere thanks are due to Mr. Cai Qingping, Mr. Chen Bicheng, and all of my lab mates for helping me and making me overcome the problems in China. Additionally, the thanks are extended to my country mates who supported me a lot during my staying in China.

My keen appreciation goes to my teachers in Egypt and in particular Prof. Fawzy M.H. Ezzat who always provides me advices all the time and for being the first who introduced me to the term Tribology.

\section{References}

[1] MKA Ali, Fuming, P., Younus, H.A., Abdelkareem, M.A., Essa, F.A., Elagouz, A. and Xianjun, H., 2018. Fuel economy in gasoline engines using A12O3/TiO2 nanomaterials as nanolubricant additives. Applied Energy, 211, pp.461-478. 
[2] MKA Ali, Xianjun H. Improving the tribological behavior of internal combustion engines via the addition of nanoparticles to engine oils. Nanotechnol. Rev. 2015;4:347-58.

[3] MKA Ali, Xianjun, H., Abdelkareem, M. A., Gulzar, M., \& Elsheikh, A. H. Novel approach of the graphene nanolubricant for energy saving via anti-friction/wear in automobile engines. Tribology International, 2018, 124, 209-229.

[4] MKA Ali, Xianjun H, Mai L, Qingping C, Turkson RF, Bicheng C. Improving the tribological characteristics of piston ring assembly in automotive engines using $\mathrm{Al} 2 \mathrm{O} 3$ and $\mathrm{TiO} 2$ nanomaterials as nano-lubricant additives. Tribol Int. 2016;103:540-54.

[5] MKA Ali, Abdelkareem, M. A., Elagouz, A., Essa, F. A., \& Xianjun, H. Mini Review on the Significance Nano-Lubricants in Boundary Lubrication Regime. arXiv preprint arXiv: 2017, 1705.08401.

[6] Abdelkareem, M. A., Makrahy, M. M., Abd-El-Tawwab, A. M., EL-Razaz, A. S. A., MKA Ali, M., \& Moheyeldein, M. M. An analytical study of the performance indices of articulated truck semi-trailer during three different cases to improve the driver comfort. Proceedings of the Institution of Mechanical Engineers, Part K: Journal of Multi-body Dynamics, 2018, 232(1), 84-102.

[7] MKA Ali, Xianjun H, Mai L, Bicheng C, Turkson RF, Qingping C. Reducing frictional power losses and improving the scuffing resistance in automotive engines using hybrid nanomaterials as nano-lubricant additives. Wear. 2016;364:270-81.

[8] MKA Ali, Xianjun H, Turkson RF, MF. E. An analytical study of tribological parameters between piston ring and cylinder liner in internal combustion engines. Proc Inst Mech Eng Part K J Multi-body Dyn. 2016;230:329-49. 
[9] MKA Ali, Hou Xianjun, Mohamed AA Abdelkareem, Ahmed Elagouz, and S. W. Sharshir. "Friction and wear reduction mechanisms of the reciprocating contact interfaces using nanolubricant under different loads and speeds." ASME J Tribol (2018).

[10] MKA Ali, Xianjun H, Elagouz A, Essa F, Abdelkareem MA. Minimizing of the boundary friction coefficient in automotive engines using $\mathrm{Al} 2 \mathrm{O} 3$ and $\mathrm{TiO} 2$ nanoparticles. J Nanopart Res. $2016 ; 18: 377$.

[11] Turkson, R.F., Yan, F., MKA Ali, Liu, B. and Hu, J., 2016. Modeling and multi-objective optimization of engine performance and hydrocarbon emissions via the use of a computer aided engineering code and the NSGA-II genetic algorithm. Sustainability, 8(1), p.72.

[12] MKA Ali, Xianjun H, Turkson RF, Peng Z, Chen X. Enhancing the thermophysical properties and tribological behaviour of engine oils using nano-lubricant additives. RSC Adv. 2016;6:77913-24. 